\title{
Honesty and inquiry: W.K. Clifford's ethics of belief
}

\author{
Nikolaj Nottelmann \& Patrick Fessenbecker
}

To cite this article: Nikolaj Nottelmann \& Patrick Fessenbecker (2019): Honesty and inquiry: W.K. Clifford's ethics of belief, British Journal for the History of Philosophy, DOI: 10.1080/09608788.2019.1655389

To link to this article: https://doi.org/10.1080/09608788.2019.1655389

曲 Published online: 29 Aug 2019.

Submit your article to this journal $\widetilde{C}$

Џll Article views: 95

Q View related articles $\triangle$

View Crossmark data $\asymp$ 


\title{
Honesty and inquiry: W.K. Clifford's ethics of belief
}

\author{
Nikolaj Nottelmann (10 ${ }^{\mathrm{a}}$ and Patrick Fessenbecker (10 ${ }^{\mathrm{b}}$ \\ ${ }^{a}$ Department for the Study of Cultures - Philosophy, University of Southern Denmark Odense

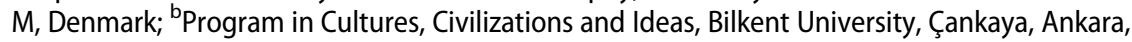 \\ Turkey
}

\begin{abstract}
W.K. Clifford is widely known for his emphatic motto that it is wrong, always everywhere, and for anyone, to believe anything upon insufficient evidence. In fact, that dictum and Clifford's condemnation of a scheming self-deceptive shipowner sum up how his ethics of belief is most often remembered and how it has been subsequently interpreted. In contrast to other recent interpretations, we argue that the motto is misleading as a guide to Clifford's position. It is best understood as essentially a rhetorical flourish. Moreover, in important ways the scheming shipowner is not stereotypical of the kind of believer Clifford thought blameworthy. A careful study of Clifford's various writings on the ethics of belief finally reveals him not to be an evidentialist in the Humean tradition. Rather, inspired by Charles Darwin's work in moral psychology, he applied an evolutionary-functional virtue ethics to the doxastic realm. This perspective allows a fruitful examination of his engagement with contemporaries like Matthew Arnold. It also allows us to recognize him as a predecessor to modern attributionist accounts of blameworthy belief.
\end{abstract}

ARTICLE HISTORY Received 31 January 2019; Revised 16 May 2019; Accepted 9 August 2019

KEYWORDS William Kingdon Clifford; Charles Darwin; Matthew Arnold; ethics of belief; ethics of religion

\section{Introduction}

With the title of his 1876 lecture 'The Ethics of Belief' (henceforth: EoB) before The Metaphysical Society, William Kingdon Clifford baptised a new philosophical field. Via his forceful declaration that 'it is wrong always, everywhere, and for anyone to believe anything upon insufficient evidence' ${ }^{\prime 1}$ (henceforth: The Motto), Clifford claimed that our duties extend beyond our actions to our beliefs (EoB 70). Moreover, he lent this principle the intuitions induced by a now-famous thought experiment: a shipowner who sincerely convinces himself that his passenger ship is seaworthy, and who makes no mention of

CONTACT Nikolaj Nottelmann nottelmann@sdu.dk D Department for the Study of Cultures Philosophy, University of Southern Denmark, 55 Campusvej, 5230 Odense M, Denmark

The authors share responsibility for the article evenly.

${ }^{1}$ Very recently, Luis Oliveira has called Clifford's Motto 'one of the most memorable lines in the history of philosophy' (Clifford, William Kingdon, [1]).

(c) 2019 BSHP 
his original doubts while quietly collecting the insurance money after it sinks. Such a man has betrayed the 'sacred faculty' of belief, Clifford argues, and is as guilty as any other killer. The Motto and the Shipowner Example have dominated the subsequent interpretation of Clifford's views: as Andrew Chignell observes: 'Clifford's essay is chiefly remembered for two things: a story and a principle' ("The Ethics of Belief", 3).

EoB was immediately controversial and has continued to be so, with criticism generally focused on two lines of objection. First, beginning with the theologian William Ward, critics objected that the evidence test implied by The Motto was misguided and self-contradictory. Observing that Clifford's empiricism required assuming the uniformity of nature, yet could not justify that assumption on the basis of evidence, they argued that many of our obviously legitimate beliefs do not - and cannot - rest on evidence. ${ }^{2}$ Secondly, critics like William James were quick to argue that surely there can be other proper grounds for belief than 'sufficient evidence'. ${ }^{3}$ Particularly in situations where the evidence is equivocal but a decision is necessary, James and subsequent writers in the pragmatist tradition have argued that believers may legitimately accept beliefs on non-evidential grounds.

Both objections, however, share the assumptions that Clifford's view emphasizes sufficiency of evidence, and that it is concisely expressed by The Motto. Indeed, even interpreters sympathetic to Clifford have accepted this approach, a fact particularly clear in the eagerness with which they have proposed new and supposedly improved versions of The Motto. ${ }^{4}$ But this interpretative emphasis ends up making Clifford's essay look extremely strange. As George Mavrodes observes, Clifford 'does not tell us how much evidence, in general, is sufficient for belief, or even how to decide how much evidence is sufficient' ("James and Clifford on 'The Will to Believe'", 212). Plus, as Susan Haack points out, to make the shipowner example the paradigm example for all cases of wrongful belief is immediately dubious, since this case has so many special features: for instance, the shipowner's belief is both false and harmful, and moreover 'willfully self-induced' ("The Ethics of Belief Reconsidered", 26). To the extent our moral reaction depends on

\footnotetext{
${ }^{2}$ See Ward, "The Reasonable Basis of Certitude", 174. Recently, this objection has been repeated with remarkable energy by Philip Smith (Why Faith is a Virtue, 44-5.)

${ }^{3}$ Will to Believe. For a recent version of the objection, see McCormick, Believing Against the Evidence.

${ }^{4}$ Examples include: Van Inwagen, "It Is Wrong Everywhere Always and for Anyone to Believe Anything upon Insufficient Evidence", 146: 'It is wrong always everywhere and for anyone to ignore evidence that is relevant to his beliefs, or to dismiss relevant evidence in a facile way' (Clifford's Other Principle). Aikin, Evidentialism, 49: 'If any subject (S) believes any proposition ( $p$ ) at any time ( $\mathrm{t}$ ), then $\mathrm{S}$ has properly done so only if: (i) $S$ has sufficient evidence at $t$ that $p$ is true, and (ii) all doubts $S$ has had (and should have) regarding $p$ 's truth or falsity has been investigated so that there are no truths $S$ could have easily discovered that would have affected S's evidence' (The Integrated Evidentialist Rule). Smith, Why Faith is a Virtue, 47:'It is wrong always, everywhere, and for anyone, to believe things that are not believed by persons for whom one has intellectual respect upon insufficient evidence' (R2). Brian Zamulinski, however, endorses The Motto with no revisions whatsoever (see e.g. "A Defence of The Ethics of Belief"; "The Cliffordian Virtue".)
} 
these features and not the mere insufficiency of evidence, the famous thought experiment doesn't support the claim Clifford implies it does. Correspondingly, Haack is puzzled why Clifford doesn't make the seemingly obvious distinction between ethical and epistemological norms. The key term supposedly at the centre of the argument - 'insufficient evidence' - ends up undefined, and Clifford's shipowner example and the subsequent arguments in the essay look like they are unrelated to the key point he wants to make.

We suggest an alternative interpretive approach: the shipowner example can only be understood against the background of Clifford's other examples of wrongful believing. And Clifford's broader view of the ethics of belief only makes sense in the context of his thinking about ethics more generally, where The Motto is better understood as a rhetorical flourish than an attempt at philosophical precision. The pleonastic and alliterative dimension to The Motto being wrong 'always, everywhere, and for anyone' is after all simply what it means for something to be wrong - hints at this. It is worth recalling too the original context of the famous text: The Metaphysical Society was an overtly polemical Victorian debating club, not a professional philosophy journal. Moreover, as Van Harvey reminds us,

It is perhaps a measure of the psychic gulf that separates the modern intellectual from his Victorian counterpart that a contemporary critic of religious belief would never appeal to some universal duty of preserving the purity of the 'sacred faculty of belief'.

("The Ethics of Belief Reconsidered", 191)

Indeed: restoring a sense of the Victorian debate about moral culture, we contend, is essential to making sense of Clifford's view of doxastic normativity.

This essay engages Clifford's position in three steps. First, in section 2 we place the shipowner thought experiment in the context of Clifford's other examples of wrongful or 'unworthy' belief (EoB 79), using the contrast that emerges to show that in Clifford's eyes the shipowner's relevant failure is not so much volitional as characterological. Blameworthiness for wrongful belief, in other words, is rooted in manifestations of bad character rather than bad voluntary decisions. Moreover, when EoB is read in the context of Clifford's December 1875 essay 'Right and Wrong: The Scientific Ground of Their Distinction' (henceforth: RaW) it becomes clear that Clifford takes his theory of doxastic duties from the broader theory of moral virtue developed by Charles Darwin. EoB poses an interpretative challenge in part because it is poised at the junction of two rich intellectual contexts: Clifford's polemic engagement with Christian apologetes inside and outside of The Metaphysical Society, and his on-going development of the Darwinian theory of morality. The former context has received too much attention, we suggest, when compared to the latter. Correspondingly, in section 3, we turn to Clifford's complex view on the ethics of normative ethical belief. We argue that Clifford's view makes most sense as an 
account of the centrality of the virtue of intellectual honesty to the Western moral tradition, an account deliberately rivalling the alternate view of that tradition held by his contemporary Matthew Arnold. Section 4 concludes.

What emerges from this reading overall is that Clifford's ethics of belief is no exercise in epistemology proper. Instead, Clifford's essay aims to apply an evolutionary-functional virtue ethics to the doxastic realm. This is a difficult position to grasp, because it does not sit comfortably within any theory of doxastic norms the field has subsequently developed. We show that Clifford is not an evidentialist in the sense he is usually taken to be, but he is not a virtue epistemologist either, at least as contemporary philosophers would typically describe that position. Instead, recovering the historical specificity of his position reveals the complexity of Darwinism's entrance into moral theory. To see this, let us begin with Clifford's cast of doxastic characters.

\section{Clifford's shipowner in context}

'The Ethics of Belief' contains at least five central examples of doxastic wrongdoing, the most famous being the much-quoted Shipowner case opening its first section ("The Duty of Inquiry"): ${ }^{5}$

(Shipowner) A shipowner notices several reasons why his passenger ship might not be fit for travel: it is old and worn, was never well built to begin with, and has often needed repairs in the past. Those were done by craftsmen not entirely trustworthy. Yet he manages sincerely to convince himself that the ship is nevertheless seaworthy, by rehearsing to himself reasons why this might be so: the ship has accomplished many previous journeys, Providence would hardly allow the passengers to die, etc. When the ship sinks and the passengers drown, he quietly collects the insurance money.

(EoB 70)

Soon follows another example:

(False Accusers) An organization agitates against a sectarian religious community, damningly accusing its members of kidnapping children. Yet, even if the accusers 'sincerely and conscientiously' believe in their charges, an appointed commission unearths evidence that the accused sect is in fact innocent. Moreover, the exonerating evidence was easily available to the accusers, had they 'attempted a fair inquiry.'

(EoB 71-2)

And a third at the end of the section:

\footnotetext{
${ }^{5}$ Clifford himself narrowly survived a shipwreck off the Sicilian coast in 1870. See Madigan, "Introduction", xiv. Scott Aikin has suggested a possible inspiration from a maritime example in Cicero's Paradoxa Stoicorum ("Evidentialism", 45-6). Perhaps a more likely source is the deeply rooted ship metaphor for the Christian church (see e.g. Bonner, "The Ship of The Soul"). Such provocative allusions were hardly lost on the learned clerical members of The Metaphysical Society. The shipowner would then be an allegorical self-deceiving parish priest, preempting Clifford's harsh 1877 attack on Christian sacerdotalism in EoR.
} 
(Tenacious Believer) A man holds a belief which he was taught in childhood or persuaded of afterwards. He keeps down and pushes away any doubts which arise about it in his mind, purposely avoids the reading of books and the company of men that call in question or discuss it, and regards as impious those questions which cannot easily be asked without disturbing it.

(EoB 77)

A new elaborate example occurs in section II ('The Weight of Authority'). We shall call this:

(Gullible Believer) A Mohammedan bases his sincere belief in the alleged divinations of Muhammed solely on various circumstantial evidence: e.g. the Prophet was a man of majestic moral character and formidable practical wisdom. His teachings have been widely accepted, and have spurred Muslim believers to social progress and glorious conquests.

(EoB 80)

Then, at the centre of section III ('The Limits of Inference'), stands the following example:

(Reckless Inference) When directing a spectroscope at the sun, a man observes a definite pattern of bright lines on the instrument's detector plate. He has previously obtained confirmation that burning hydrogen is the source of this pattern, when earthly bodies are examined. But without understanding the exact workings of the spectroscope or considering any general principles covering both extra- and intra-terrestrial cases, he immediately arrives at the belief that the sun contains burning hydrogen.

(EoB 93-4)

In what sense does Clifford consider the beliefs of those five doxastic villains 'wrong'? A tempting idea is that Clifford primarily saw their beliefs as wrong in the sense of being epistemically unjustified. At least, The Motto's link between wrongness and insufficient evidence would suggest so. Yet, Clifford also thinks that all five believers are morally at fault due to their beliefs. The shipowner is 'guilty for the death of those men [his passengers]' (70), while the tenacious believer's life is a 'sin against mankind' (77), and the gullible Muslim 'has made of his [the Prophet's] goodness an occasion to sin' (84). Even the reckless inferrer, who might seem a more innocent sort, is not off the hook: Clifford insists that a belief lies on 'unworthy grounds' when it exists 'without some understanding of the process, by which it is got at' (94).

One way to read Clifford's main point here is to saddle him with the view that epistemically unjustified belief is morally wrong tout court. This is Susan Haack's suggestion:

The main thesis of that paper is that 'it is wrong always, everywhere, and for anyone, to believe anything upon insufficient evidence'. Neither here nor elsewhere in the paper does Clifford ever distinguish 'it is epistemologically wrong' from 'it is morally wrong.' But he offers no argument for identifying the two, or even for the special-case thesis, that the former is a sub-species 
of the latter. Instead, extrapolating from a striking case [the ship owner] where unjustified believing is culpable ignorance, he tries to persuade one that all cases of unjustified believing are, in some measure, both harmful and willful.

("The Ethics of Belief' Reconsidered", 135)

Haack thus maintains that Clifford's main argument turns on arguing that moral wrongness and epistemological unjustifiedness are correlated, due to their joint occurrence in the Shipowner case. But one might consider instead the possibility that Clifford's supposed error in failing to explicitly introduce a conception of epistemic justification is not a failure, but instead a hint of his real position. It is worth noting in this light that the lack of epistemic justification seems inessential to his moral condemnation of the five doxastic villains: in (Shipowner), Clifford focuses not on the nature of the shipowner's final evidential base, but rather on the motivation guiding this villain's belief-forming process: 'He had acquired his belief not by honestly earning it in patient investigation, but by stifling his doubts' (EoB 70). Similarly, for the false accusers, 'their sincere convictions, instead of being honestly earned by patient inquiring, were stolen by listening to prejudice and passion' (82). Meanwhile the gullible believers' blindness to the distinctive relevance of the Prophet's competence, Clifford insinuates, must be motivated by a desire for personal comfort (83). Such motivations, Clifford clearly thinks, should play no role in believing. While beliefs may indeed bring 'happiness and security' or a 'sense of power', that sense 'is stolen in defiance of our duty to mankind' if it 'has not been fairly earned in investigation' (75).

Clifford leaves no doubt that by 'wrong' he means morally blameworthy: doxastic wrongdoing is 'sinful' (EoB 75) and 'dishonourable' (72). But how did Clifford ground such verdicts? The intricacy involved here deepens when we note Clifford's insistence that the shipowner's blameworthiness does not depend upon the bad consequences of his belief:

Let us alter the case a little, and suppose that the ship was not unsound after all; that she made her voyage safely, and many others after it. Will that diminish the guilt of the owner? Not one jot. When an action is once done, it is right or wrong for ever; no accidental failure of its good or evil fruits can possibly alter that.

(EoB 71)

Yet he quickly seems to qualify this anti-consequentialist attitude: in further defence of the viciousness of doxastic wrongdoing, Clifford stresses how even seemingly slight doxastic sins like those committed by 'the rustic in the village alehouse' (75) risk plunging society 'back into savagery' (76).

A first idea could be that, as Brian Zamulinski argues, Clifford endorsed a version of rule-consequentialism. In other words, Clifford assumed what Brad Hooker has termed an 'expectabilist rule-consequentialist criterion of

\footnotetext{
${ }^{6}$ This criticism is repeated in Chignell and Dole, "The Ethics of Religious Belief: A Recent History", 4.
} 
blameworthiness': an act is blameworthy if and only if it is forbidden by the rules the acceptance of which would result in the greatest expected good ("Rule Consequentialism", 22). Implicitly we are asked to infer that by 'stifling his doubts' (EoB 70), the shipowner violates a rule accordance with which would maximize expected moral good. As Zamulinski puts it, Clifford holds that ' $[e]$ ndangering others can be condemned on consequentialist grounds because there is an overhigh probability that the act that endangers others will result in harm to them' ("A Defence of The Ethics of Belief", 83). Yet, we submit, reading Clifford as a rule-consequentialist goes against key passages of EoB and makes that essay incongruous with RaW in easily avoidable ways. Consequences were of moral importance to Clifford in a way even more indirect than rule-consequentialism can allow. ${ }^{7}$

In some parts of EoB, Clifford clearly disavows consequentialism, as in his insistence that the source of the shipowner's guilt lies exclusively in the origin of his belief (71). What needs careful consideration, then, are those passages where Clifford seems to embrace a consequentialist metaethics by elaborating on the social harms likely to result from blameworthy belief. We suggest untying this knot by appeal to Clifford's implicit Darwininism. As has been thoroughly documented by Josipa Petronic, Clifford's philosophical views on natural science and mathematics were strongly influenced by recent developments in evolutionary theory from his early undergraduate years at Cambridge onwards ("Evolutionary Mathematics"). By the time of his late triad of popular essays (RaW, EoB, EoR), this influence clearly permeates his metaethical views:

[T]he question about the best conscience will resolve itself into a question about the purpose or function of our conscience - why we have it and what it is good for. Now to my mind the simplest and clearest and most profound philosophy that was ever written upon this subject is to be found in the $2^{\text {nd }}$ and $3^{\text {rd }}$ chapters of Mr. Darwin's Descent of Man.

(RaW 62)

Crucial to Darwin's meta-ethics in Descent of Man Chapters 2-3, and accepted without reservations in $\mathrm{RaW}$, is the idea that the moral good may be identified with the direction of human consciousness when it perfectly fulfils its evolutionary purpose. In Clifford's words:

The function of conscience is the preservation of the tribe as tribe. And we shall rightly train our consciences if we learn to approve those actions which tend to the advantage of the community in the struggle for existence.

(RaW 62)

And further

\footnotetext{
${ }^{7}$ Zamulinski insists that charitably Clifford must be read as a consequentialist, since 'consequentialism is the only plausible game in town when it comes to the ethics of belief' ("A Defence of The Ethics of Belief", 80). This, however, is a not a universally shared position. The literature is rife with deontological and functional accounts (see. e.g. Section IV below).
} 
The first principle of natural ethics, then, is the sole and supreme allegiance of conscience to the community. I venture to call this piety in accordance with the older meaning of the word.

$(\text { RaW 66) })^{8}$

Like his great tutor, Clifford dismisses any hedonistic conception of the basic moral good. Conscience, he submits, is best aimed at 'the greatest efficiency of all citizens as such' (RaW 67). This somewhat puzzling notion echoes Darwin's famous statement that 'the term general good, may be defined as the means by which the greatest possible number of individuals can be reared in full vigour and health, with all their faculties perfect, under the conditions to which they are exposed' (Descent of Man, 833). ${ }^{9}$

To some extent, in fact, the argument in EoB may be read as an elaboration upon a brief passage in the Descent of Man. Expressing admiration for 'the love of Truth', Darwin writes at one point that '[t]he highest stage in moral culture at which we can arrive, is when we recognize that we ought to control our thoughts' (835). Clifford's popular essays may be regarded, we contend, as an effort towards explaining more exactly the interactions between 'the love of Truth' and 'moral culture.' By the end of RaW, Clifford lays the foundation for its descendant EoB:

Veracity to an individual is not only enjoined by piety in virtue of the obvious advantage which attends a straightforward and mutually trusting community as compared with others, but also because deception is in all cases a personal injury. Still more is this true of veracity to the community itself. The conception of the universe or aggregate of beliefs which forms the link between sensation and action for each individual is a public and not a private matter; it is formed by society and for society.

(RaW 68)

To sum up Clifford's position here: doing moral good requires piety (the allegiance of conscience to the community), which again requires the derivative virtue of veracity, not only toward other members of society, but also toward oneself as aimed at the benefit of society. Scott Aikin rightly points out that there is an echo of Stoic themes here, particularly insofar as Clifford's view like that of the Stoics 'integrates elements of consequentialist reasoning to identify duties' (Evidentialism, 46-7). However, the

\footnotetext{
${ }^{8}$ Curiously, without any reference to Clifford, prominent atheist philosopher Louise Antony has recently insisted that regarding moral value as immanent in the natural world is in fact a highly pious position, the only way adequately to explain why we should hold such values sacred ("Good minus God").

${ }^{9} \mathrm{Clifford}$ even follows Darwin in quickly skipping what seems like one of the most difficult challenges for the theory: If human consciousness was evolved through group-level natural selection in order to boost the evolutionary fitness of small social units (or 'tribes') in their competition with other such units, how come that morality seems concerned with the universal good of mankind? Here Clifford holds it 'clear that for the purpose of conscience the word 'community' at any time will mean a group of that size and nature which is being selected or not selected for survival as a whole' (RaW 64). And without much ado he concludes: 'Thus we have a sense of family duty, of municipal duty, of national duty, and of duties towards all mankind' (RaW 64).
} 
same goes for a Darwinian functionalist metaethics. ${ }^{10}$ And as we argue here, in RaW Clifford clearly committed himself to this position in ways that resonate well with EoB.

In this round-about way, then, Clifford comes close to endorsing a rule-consequentialist criterion of moral blameworthiness, but on the Darwinian view an action (or a belief) is never blameworthy solely because it violates rules that would prospectively maximize the moral good if universally respected. Rather it is blameworthy because a perfectly functioning conscience would have prevented that action (or belief). A perfectly functioning conscience, in turn, is a conscience aimed at maximizing the moral good (not least through inducing in its owner respect for rules of veracity) where this is conceived as the evolutionary fitness of the agent's community. ${ }^{11}$

The Darwinian framework is moreover valuable for making sense of a key element of Clifford's argument: his strict uniformism, or the literal insistence that everyone should question 'all that [they] believe' (EoB 75). In EoB, his fire-and-brimstone sermonic style often makes it seem as if Clifford bases this normative thesis only on the (somewhat dubious) empirical claim that even the slightest breach of this rule by anyone risks disastrous social consequences. This has clear consequentialist overtones, yet plausibly a uniform skeptical attitude is hardly ideal for scientific or social progress. ${ }^{12}$ But on a theoretical level Clifford is committed to uniformism because, like Darwin, he regards conscience as working perfectly when exerting a basic motivational force preventing the onset of socially harmful mechanisms in the

\footnotetext{
${ }^{10}$ Evidence of the evolutionary shaping of traits like veracity by the ancestral adaptive habitat will hardly show up in the palaeo-anthropological record. Unlike in the case of homo sapiens adaptions like lighter bone structure, the evolutionary theorist has to rely on historical evidence of the well-functioning of veracity and extrapolate backwards to prehistoric times. This commitment to observed positive consequences of manifested veracity must not be confused with a consequentialist account of veracity's moral significance: it is complex in a way a consequentialist meta-ethics cannot easily account for. From the supposition that the evolutionary function of some adapted trait must be established by its observed positive consequences, it does not follow that in order to function well this trait must produce such positive consequences always and under all possible conditions.

${ }^{11}$ If all this is correct, one might well wonder why Clifford didn't just say so. Why, in other words, did Clifford choose not to articulate his Darwinian commitments clearly in EoB? We speculate that the answer is more rhetorical than substantive. First, his Darwinism must have been perfectly well known to his audience, having appeared so prominently in RaW; this essay was published in the Fortnightly Review in December 1875, a few months before Clifford gave his EoB lecture to the Metaphysical Society on April 11th 1876. Secondly and more importantly, EoB is not an essay in metaethics: it is something closer to Clifford's attempt at a sermon. Mimicking this genre, he quotes as authorities not only the Bible ('Who hath made Israel to sin?', alluding to 1 Kings 14:16, EoB 77) but also Christian poets like Milton and Coleridge (77-78).

${ }^{12}$ Notice how Van Harvey makes Clifford's uniformism more palatable by stipulating that implicitly Clifford must have prophesised of norms befitting a future 'form of life' in which uniform criticality would indeed matter essentially ("The Ethics of Belief Reconsidered", 200). On this matter, again, Zamulinski stands out as an uncompromising defender of Clifford's risk assessments, but Rik Peels has argued that Zamulinski relies on the dubious claim that overbelief must always involve the relaxation of one's personal evidential standards. ("The Ethics Of Belief and Christian Faith as Commitment to Assumptions", 104). Rowbottom's 'Kuhn vs. Popper on Criticism and Dogmatism in Science' argues that social and scientific progress is better served by a division of labour between skeptics and dogmatists.
} 
individual. Since we are all individual members of the same species, the same 'society' in the largest sense, we share the same basic moral psychology and are all subjects to the exact same moral norms. And since the shape of those norms rests on the proper functioning of the individual organism's basic motivational structure, there is no room for those norms to distinguish between members of the same species or for those norms to distinguish between various beliefs arising from the same basic motivational mechanisms.

Also, as we shall investigate more fully in section III below, Clifford's otherwise puzzling stance towards fundamental normative and metaphysical principles makes much more sense within a Darwinian framework. Such principles, Clifford submits, may be 'refined' and 'chastened', even if ultimately they can never be fully grounded in evidence (EoB 93). Merely preserving the status quo most likely is disadvantageous to society. A well-functioning social unit must be poised for moral and scientific development. As Clifford wrote in his 1868 'On Some of the Conditions of Mental Development': 'To become crystallized, fixed in opinion and mode of thought, is to lose the great characteristic of life [ ... ] the power of adapting itself to circumstances' (105). Now, like Hume before him, Clifford believed there could be no scientific practice without reliance on basic principles in inferences (EoB 93). Thus, it becomes morally permissible, even obligatory, to believe in versions of such principles, even if they are not based on evidence (see, however, Rescher Pascal's Wager, 144).

Now, it might seem a problem that, at the time at which allegedly Clifford's doxastic villains believe in blameworthy ways, they each seem ignorant of the bad-making features of their beliefs. The false accusers 'believed sincerely and conscientiously in their charges' (EoB 72). The gullible Muslim does not even begin to question the divine inspiration of his prophet. And the reckless inferrer hardly even understands the scientific minutiae required responsibly to draw the relevant inference. This implication points to an important and surprising claim: it does not matter whether a believer cunningly tricks himself into a comfortable state of belief or whether he is too simple-minded to challenge it. 'No simplicity of mind, no obscurity of station,' Clifford writes, 'can escape the universal duty of questioning all that we believe' (EoB 75). To use a modern theoretical term, we contend that Clifford was strongly committed to a radical attributionist position: he held an agent's moral blameworthiness not to derive fundamentally from her bad voluntary decisions, but rather from the manifestations of her imperfect character, voluntary or not. $^{13}$ It is unfortunate that the Shipowner and Tenacious Believer examples

\footnotetext{
${ }^{13}$ For an account of the contrast between attributionism and volitionism, see e.g. Levy, "The Good, the Bad and the Blameworthy." Mainstream modern attributionism in the ethics of belief sprang from NeoKantian roots, not least Scanlon's What We Owe to Each Other. Recently, however, several authors have advanced attributionist positions much closer to Clifford's: 'agents can, in principle, be thought of as responsible for actions that reflect upon their deep selves, even if those actions are non-conscious, non-volitional, and ... do not trace back to some previous action or decision.' (Brownstein, "Attributionism", 767).
} 
misleadingly suggest the opposing idea of volitionism, the position that blameworthy belief invariably arises through blameworthy voluntary decisions like the shipowner's cowardly engagement in self-deception. Importantly, Clifford's other villains have no similar explicit backstory of voluntary benighting behaviour. ${ }^{14}$ Rather, what all villains share are manifestations of deep-seated dispositions directed away from the moral good. In sum, Clifford is ready to declare morally blameworthy all beliefs manifesting a subject's character traits directed away from contributing to society's moral-scientific progress.

How could we fairly blame people on account of manifesting their vicious character if they did not manifest it voluntarily? In RaW, Clifford makes short shrift of this objection: 'When I look back and reflect upon a voluntary action, I seem to find that it differs from an involuntary action in the fact that a certain portion of my character has been consulted' (52). Elaborating on this observation, Clifford then suggests that full responsibility only requires that an agent's 'mental character' determines his course of action, and that this only requires a 'conscious consultation of [his] past history' (52). In EoB, his villains are shaped by their deep-seated dispositions for responding to evidence and thus form beliefs in specific and distinctive ways. To Clifford, this removes any reason for exonerating them on account of 'involuntariness'.

With this approach in place, let's return to The Motto's criterion of 'insufficient evidence'. As noted earlier, Clifford offers frustratingly little in explaining how much evidence is needed for belief to be blameless. His villains, moreover, seem to suffer from evidential insufficiency in very different ways: the shipowner accessed a wide body of evidence, but ended up basing his belief on a skewed portion of it due to his wilful self-deception. The false accusers had only accessed a minor portion of their accessible evidence due to their indolence in inquiry. The gullible religious believer, due to his gullibility, rested his case on ample evidence of Muhammad's sincerity, but without taking into account relevant evidence regarding the true source of Muhammad's beliefs. The tenacious believer on the other hand deliberately ensures that all his salient evidence supports his belief, by strategically lowering his likelihood of confronting counter-evidence. The reckless inferrer finally does not even have to deal with counter-evidence. His 'sin' solely consists in believing while lacking evidence supporting his conclusion that his measuring apparatus works similarly under differing conditions. It seems very difficult to put those cases on a common evidential denominator.

Fortunately for Clifford, this issue is a red herring. Importantly, he uses 'insufficient evidence' and 'unworthy evidence' interchangeably, as here:

\footnotetext{
${ }^{14}$ Holly Smith's apt term. See her "Culpable Ignorance", 547.
} 
But because it is not enough to say, 'It is wrong to believe on unworthy evidence,' without also saying what evidence is worthy, we shall now go on to inquire under which circumstances it is lawful to believe on the testimony on others; and then further, we shall inquire more generally when and why we may believe that which goes beyond our own experience, or even beyond the experience of mankind.

(EoB 79)

Worthy versus unworthy evidence invokes a much different distinction than the continuum implied by the notion of a scale of evidence on which a certain point marks sufficiency. 'Unworthy evidence' seems rather more felicitously understood as evidence which a subject is blameworthy for believing upon under the relevant circumstances. If 'unworthy evidence' is in fact as central to Clifford's view as the text suggests, then the 'insufficient evidence' test is best understood as a heuristic, one way among several of testing whether one's evidence is worthy. Assuming 'insufficient evidence' and 'unworthy evidence' share one common speaker meaning in EoB, the common denominator of Clifford's doxastic villains, then, is not the insufficiency of their evidence understood along evidentialist lines but rather their unworthiness in belief. Each villain manifests a cardinal moral-doxastic vice by believing as he does under his circumstances: proneness to self-deception, indolence in inquiry, gullibility, and so forth. This resolves the puzzle why Clifford does not bother to explain his notion of evidence, but spends considerable effort canvassing the viciousness of his villains. Even if clearly some passages of EoB suggest an evidentialist position, the notion of evidence ultimately is peripherical to his concerns. We speculate that he used the expression 'insufficient evidence' in The Motto simply to avoid stating an overt tautology, since 'It is wrong to believe on unworthy evidence' says very little, especially in light of his later explanation that unworthy evidence is simply the kind of evidence it is not 'lawful' to believe upon (EoB 79). ${ }^{15}$

It is unfortunate that Clifford says so little about believing worthily or admirably. There are no doxastic saints in EoB to atone for the misdeeds of its doxastic sinners. We are assured only that

There is no practical danger that such [skeptical] consequences will ever follow from scrupulous care and self-control in the matter of belief. Those men who have most nearly done their duty in this respect have found that certain great principles, and these most fitted for the guidance of life, have stood out more and more clearly in proportion to the care and honesty with which they were tested, and have acquired in this way a practical certainty.

(EoB 78-9)

\footnotetext{
${ }^{15}$ Also, plausibly by The Motto Clifford meant to invoke in his listeners' minds David Hume's famous dictum that 'a wise man proportions his belief to his evidence' (Enquiry X.1 ['On Miracles'], 87). EoB's early implicit allusion to the notorious Scottish infidel must have stirred a murmur among The Metaphysical Society's zealots, priming them for an assault on doctrinal belief similar in harshness to Section X of Hume's first Enquiry.
} 
It may be nice to know that the manifestation of doxastic virtue does not require a universal suspension of belief. But it is hardly very comforting to learn that even the best among us have only 'most nearly done [our] duty'! Clifford seems to convey the stern message that only the impossibly selfless may hope to escape blame on account of their beliefs: EoB is a call for moral contrition, not a celebration of scientific virtue.

This indeed is part of the rhetorical function of the essay, which is perhaps best categorized generically as a secular sermon. According to Clifford we enjoy at least some indirect control over our characters and how they manifest themselves:

Every time we let ourselves believe for unworthy reasons, we weaken our powers of self-control, of doubting, of judicially and fairly weighing evidence [... ] a greater and wider evil arises when the credulous character is maintained and supported, when a habit of believing for unworthy reasons is fostered and made permanent.

(EoB 76)

Calling to mind one's moral duties with regard to honesty and veracity on Clifford's view may prevent one's vicious character from manifesting itself in blameworthy belief, and indirectly may thereby prevent its further deterioration. Conversely, Clifford emphasizes the contagious nature of doxastic vice: the credulous believer 'fosters a credulous character in others' (76). It seems no mere allegory when Clifford revels in the future eviction of doxastic sinners from 'the pure and holy temple of science' (92). Ascribing blameworthy belief marks 'sinful' believers for social condemnation and serves for harnessing their powers of self-improvement. EoB is as much an attempt to change the world as it is to understand it.

\section{Clifford versus Arnold on the ethics of moral belief}

Rather provocatively EoB did not to any significant degree address The Metaphysical Society's previous debates, even if it spurned intense public argument among its members and may even have precipitated the society's 1880 dissolution (Madigan, W.K. Clifford and The Ethics of Belief, Chap. 4.I.1-2). This was hardly an accident. Clifford's primary target lay elsewhere, in a theory of religion that minimized its status as a set of beliefs and claimed instead that a distinct kind of moral consciousness was at its essence. Making sense of Clifford's view of doxastic normativity and his corresponding theory of moral culture requires briefly returning to that rival.

Clifford addresses a view that, at its most blunt, holds that one might choose to believe a religious claim even while knowing it to be false. As he describes it in 1877 in 'The Ethics of Religion' (henceforth: EoR), '[t]here is a meaning of the word religion which has been coming more and more prominently forward of late years, till it has even threatened to supersede all the 
others. Religion has been defined as morality touched with emotion' (101). Clifford leaves his rival unnamed, but the famous source for this definition is Matthew Arnold's Literature and Dogma (henceforth: LaD). Arnold saw 'culture' as a humanistic tradition, defining it as 'the best that has been thought and said', and in LaD he offers a sort of cultural defence of the religious tradition ( $\mathrm{LaD}$ xiii). He argues initially that the word 'God' is 'by no means a term of science or exact knowledge'; it is rather 'a literary term' (LaD 12). Readers of the Bible should regard religious claims in that light. They must abandon the skeptical approach of the 'philosophical liberals' like Herbert Spencer but should also ignore the ill-motivated attempts of theologians to render Christian belief precise. These two parties are really Victorian equivalents of the Pharisees and Sadducees (LaD 370).

The earliest Jews, according to Arnold, understood religious life better than many of their heirs: they saw 'the Eternal' not as a philosophically definable First Cause, but instead as a 'not ourselves which is in us and around us' that 'makes for righteousness [...] unchangeably and eternally' (LaD 32). The proof of this 'Eternal' is practical, and the belief is verifiable the same way one can 'verify that fire burns, by experience!' (LaD 293): moreover, 'nations and men, whoever is shipwrecked, is shipwrecked on conduct. It is the God of Israel steadily and irresistibly asserting himself' (LaD 350). In short, both persons and human societies are constituted in such a way that the Christian tradition is their best route to flourishing.

As we saw above, Clifford doesn't bother addressing the possibility that beliefs might be false but individually beneficial because he doesn't believe that individual benefits are at all relevant for the normative status of beliefs. Doxastic norms, like all norms, stem from the conditions that contribute to the fitness of a society, and the possibility that a belief might be personally pragmatically useful is immaterial to the question of its moral value. But that leads to a corresponding objection Clifford is quite worried about: what about public benefits? Are there cases where a belief might be false but publicly beneficial, especially when held by many members of a society? Certainly, this is one way of construing Arnold's answer about the ultimate justification of Christianity: widespread Christian beliefs contribute to a nation's political success. Clifford's own answer is a clear no; as he puts it near the end of RaW, 'we should lose infinitely more by nourishing a tendency to falsehood than we could gain by the delusion of a pleasing fancy' (69). Here the real difference between Clifford and Arnold emerges: more than simply disagreeing on the justification of religious belief, they disagree on the nature of moral culture, and Clifford's distinctive contribution lies in his contention that honesty is at the centre of moral life. ${ }^{16}$

\footnotetext{
${ }^{16}$ In thinking thus, his view reflects another component of Victorian moral thought: the emphasis on what Walter Houghton calls 'earnestness'; see Victorian Frame of Mind, 218. This was a cultural shift apparent at the time; John Kucich notes that the 'momentous inflation of the cultural cachet of honesty [that] took place in Victorian England' was certainly clear to 'nineteenth-century observers'; see Power of Lies, 5.
} 
Treatments of Clifford have generally ignored his stance on specifically moral beliefs, presumably because these seem so clearly not to be based on evidence and thus to be a minor topic unrelated to the main point of EoB. Yet once we move away from understanding Clifford as primarily an evidentialist, moral beliefs turn out to run parallel to beliefs about the world and to admit of evaluation in the same way - based on whether they reflect a character oriented towards the social good. Clifford's close link between moral beliefs and other sorts of belief becomes apparent in the following passage:

Religious beliefs must be founded on evidence: if they are not so founded, it is wrong to hold them. The rule of right conduct in this matter is exactly the opposite of that implied in the two famous texts: 'He that believeth not shall be damned,' and 'Blessed are they that have not seen and yet have believed' [ ... ] Whoever wrote either of them down as a deliverance of one whom he supposed to be a divine teacher, has thereby written himself down as a man void of intellectual honesty, as a man whose word cannot be trusted, as a man who would accept and spread about any kind of baseless fiction for fear of believing too little.

$\left(\right.$ EoR 102) ${ }^{17}$

What is striking here is that a (widely held) moral view is portrayed as a doxastic failure. If one believes on the one hand that a given moral teacher should be regarded as divine, and on the other hand that this person was speaking divinely in praising belief without or against evidence, then that in itself is an unjustified combination of beliefs, a failure of 'intellectual honesty'. There's no obvious logical contradiction here, but instead something like a practical violation. To believe it is virtuous to believe without evidence is to fail to manifest the virtue of honesty.

As Zamulinski observes, however, Clifford was no 'tub-thumbing village atheist', and his relationship to Arnold's approach is more complex than it might seem ('A Re-evaluation of Clifford and His Critics', 453). Both writers agree, after all, on the importance of doxastic culture, and are even both inclined to use religious overtones in describing it, as one famous passage from EoB makes clear: 'He who makes use of its [the sacred tradition of humanity's] results to stifle his own doubts, or to hamper the inquiry of others, is guilty of a sacrilege which centuries shall never be able to blot out' (EoB 91-92). ${ }^{18}$ Of course Clifford is inclined to give this importance an evolutionary explanation: if believing is associated with certain behaviours, and is moreover socially contagious, clearly the beliefs of its members matter to the evolutionary fitness of a community. Thus, where Clifford

\footnotetext{
${ }^{17}$ Unsurprisingly Arnold has a much different attitude toward these passages. He considers the latter, from the Book of John, as clearly a genuine statement from Christ, one whose truth surpasses the inadequacy of the Gospel narrators (LaD 279).

${ }^{18}$ It's worth noting in passing that both writers seem thus to reject the Humean conception of belief as consciously occurrent, or as Hume puts it 'a lively idea related to or associated with a present impression' (Treatise I.III.VII, 96). Rather beliefs can be 'stored up' and are much more closely linked to action: as Clifford writes, belief 'knits into harmonious working all the compacted energies of our being' (EoB 74).
} 
takes a departure is in which parts of that culture are essential to it and which parts merit preserving. Against Arnold's respect for Christian culture, Clifford reminds us of its failures: religion contains 'immorality touched with emotion' alongside its more positive opposite (EoR 100). So far from religion reflecting morality as such it's essential that morality be kept apart in order to evaluate religion: the 'tribunal of conscience [is] the supreme judge of men and Gods' (EoR 102).

This view would be straightforward if Clifford thought of morality as a set of moral truths ascertainable by study of the evidence, but unfortunately things are not so clean, for Clifford is inclined to view morality both as admitting of changes over time and as depending on the intuitive basis of moral feeling. ${ }^{19}$ It's easier to see what Clifford would say if one looks at his account of the evolution of our assumption of the uniformity of nature. When we start investigating the world, we cannot help but assume that nature is uniform - that a stone which is heavy in the morning will be heavy in the afternoon (RaW 37). Such non-evidential beliefs are not 'wrongful' per se, since they are needed to achieve any kind of progress. But at first our assumption is naive and vague, and it will be 'chastened and corrected' as we learn about the world. So, for instance, I might discover that although the stone's heaviness doesn't change over time, it does change if I move it into space. Thus, assumptions about uniformity get more specific: in Clifford's words, 'I begin by assuming that it is independent of everything; I end by finding that it is independent of some definite things' (RaW 38). Instinctive assumptions of uniformity improve over time, and subsequently 'goes to form the more precise instinct of the next generation' (RaW 39). In an example we'll return to, Clifford offers the history of beneficence as roughly analogous: people have a basic moral instinct, yet the more they learn about the actual necessary conditions for social coherence, the more informed ('chastened and corrected') that instinct becomes.

This then is the context for the sharp twist Clifford gives to the notion of the moral tradition in EoB. Rather than a collected accumulation of moral wisdom, or Arnold's sense of a transcendent vague experience of 'righteousness', Clifford regards it as residing above all in our practices of inquiry: 'in questions rightly asked, in conceptions which enable us to ask further questions, and in methods of answering questions. The value of all these depends on their being tested day by day' (EoB 91). When the tradition does include facts and claims, moreover, they come packaged with the surrounding questions and arguments. Clifford gives us the example of Ohm's law, which holds that the voltage and current of an electric circuit are directly related, while they are inversely related to the resistance (if any) in the circuit (EoB 90).

\footnotetext{
${ }^{19}$ As he puts it: 'We say that it is wrong to murder, to steal, to tell lies, and that it is right to take care of our families. When we say in this sense that one action is right, and another wrong, we have a certain feeling towards the action which is peculiar and not quite like any other feeling' (RaW 31).
} 
But 'the result', Clifford explains, 'is not the valuable part of it. The first half is the question: What relation holds good between these quantities?' (EoB 91). In other words, what is really salient about Ohm's law is not the law itself, but the decision to ask about the relationship between voltage, current and resistance in the first place. So long as we hang onto that, knowing the law itself is not particularly important.

Thus we do not violate the moral tradition by, say, questioning religiouslyinflected moral principles. In fact, asking this kind of question and pressing on how best to understand and act on our moral feeling is precisely what the tradition asks us to do and what it has long done. In terms of moral knowledge, development of the tradition correspondingly consists of inquiring after and recognizing a link between existing practices and primitive moral feelings. Thus 'the rough condemnation of stealing carries with it a condemnation of more refined forms of dishonesty; we do not hesitate to say that it is wrong for the tradesman to adulterate his goods, or for a laborer to scamp his work' (RaW 30). So, one might say that the inquiry here is asking if it is stealing for a grocer to mix his flour with sawdust. As with Ohm's law, this way of putting the question conveys everything that needs to be conveyed, while memorizing the slogan 'adulterating goods is wrong' threatens to become meaningless if stripped of the inquisitive process that led to it.

This account leaves several puzzles, one that Clifford addresses at some length and at least one where his answer is less clear. First, his explanation of the moral tradition plays a central role in explaining why 'the universal duty of questioning all that we believe' doesn't end in paralysis or moral skepticism (EoB 75). Our ordinary habits are more reliable than one might think: the 'practical certainty' inhering in the 'great principles' of the moral tradition is like that of Ohm's law, since we feel and thereby verify the link between moral justification and specific practice in acting (EoB 79). Then too, sometimes the provisional adoption of a belief is a necessary step to figuring out whether it is true: 'it is precisely by such action, and by observation of its fruits, that evidence is got which may justify future belief'. ${ }^{20}$ But at the same time, Clifford thinks we should probably be more paralyzed than we currently are. This is the rhetorical force lying behind his blunt response to one imagined interlocutor. In a famous passage, Clifford writes:

'But,' says one, 'I am a busy man; I have no time for the long course of study which would be necessary to make me in any degree a competent judge of certain questions, or even able to understand the nature of the arguments.' Then he should have no time to believe.

(EoB 78)

\footnotetext{
${ }^{20}$ Given his sympathetic description of Mill as a 'noble thinker,' (RaW 69) we should probably see Clifford as invoking here Mill's famous notion that there can be 'experiments in living' - habits and activities whose worth may not be conclusively known, but which are worth trying out. On Liberty, Ch. III.
} 
Given his account of the nature of the moral tradition, it's clear why Clifford thinks this: very little one does is as important as what one believes, and to try to justify a belief on the grounds of the higher priority of some other activity demonstrates a morally flawed sense of one's relationship to society. What Aikin calls Clifford's 'epistemic infinitism' views the project of knowing as an endless pursuit of critical questions, and correspondingly asserts the importance of 'a cognitive culture that provides its members with the desire and skill to pursue that project' (Evidentialism, 69). This form of skepticism is thus liberating and stimulating. It turns each of us into an eager inspector, seeing each individual moment of believing as a step in the great collective project of understanding the universe.

Clifford's answer to a related issue, however, is less clear. Recall his confidence that no skeptical pursuit of the evidence, no matter how searching, ultimately threatens core moral beliefs: the 'great principles' of moral life are only proven more thoroughly when they are 'tested' (EoB 79). Clifford's certainty seems unwarranted, and it is made more puzzling by the fact that Clifford also concedes that there has been moral progress involving the revision of moral beliefs. In an example that is perhaps more fitting than he intended, he writes that we have a basic instinct of beneficence, and this instinct generally leads us to pity the poor and want to give them money. However, 'the questioning of this rule, and investigation into it, led 'men to see that true beneficence is that which helps a man to do the work which he is most fitted for, not that which keeps and encourages him in idleness' (EoB 89). That sort of reflection upon a moral instinct develops it, and in turn it helps correct our conception: 'by the continual asking and answering of such questions the conception grows in breadth and distinctness, and the instinct becomes strengthened and purified' (EoB 89). But the broader picture is much less clear, bordering on paradoxicality. Clifford seems to be reassuring his audience that their moral beliefs are essentially correct and will not suffer from further investigation, yet also that there has been significant moral progress through the change of moral beliefs precisely through investigation. It's tough to see why he thinks he has a rational basis for concluding that further progress won't continue to undermine widely held moral beliefs, not least because the thorough rejection of Victorian assumptions did in fact lead to such progress. ${ }^{21}$ The picture of Victorian workhouses and the New Poor Law's penalties on vagabonds Clifford praises here makes the point rather neatly: we have continued to 'ask and answer' questions about how best to be beneficent, and recognized that in fact modest welfare programmes do not 'encourage' idleness.

\footnotetext{
${ }^{21}$ Clifford's regrettable commitment to at least some of these assumptions appears in his distinction between the 'more civilised nations of Europe,' for instance the 'German and Dutch,' and the 'savage' societies of Africa, although to his credit even in London he finds 'an atmosphere of beliefs fit only for the savage' (EoB 87-88).
} 
Presumably, the core of Clifford's response to the problem here - the paradox of a moral tradition that is somehow always true yet always improving - is an idea which is hardly unique to him: what is going on is not change but purification. To the extent there is novelty in moral truth, it comes insofar as the changing world of social practice will need to be continually investigated by thoughtful observers. Inquiry always continues and must continue, but it is fundamentally motivated by the selfless duty of honesty, and honesty cannot call itself into question. There may well be no firm moral truths, if by 'truth' one means confidence in the judgement of the timeless moral value of some particular practice, but the core moral feelings underlying that judgment do not themselves change.

\section{Conclusion}

We have presented an interpretation of Clifford's ethics of belief, unearthing its deep roots in an orthodox Darwinian version of a functionalist metaethics. Moreover, we have dismissed the volitionist reading naturally suggested by Clifford's widely known shipowner example, replacing it with an attributionist interpretation more naturally covering his full range of salient cases. Correspondingly, we have offered an interpretation of Clifford's complex attitudes towards moral belief, showing how his account of the moral and scientific culture that comprises the 'sacred tradition of humanity' rivalled Matthew Arnold's prominent and radically different conception of the same history. It turned out that Clifford's project was not defending an evidentialist epistemology. Moreover, he was not a virtue epistemologist in any sense different from his being an evolutionary-functionalist virtue ethicist applying this ethical theory to the doxastic realm. Clifford's primary concern was always with moral virtue as grounded in the evolutionary fitness of human collectives. ${ }^{22}$

Even if in our reconstruction Clifford's ethics of belief lacks full-fledged modern disciples, several of its central ideas remain alive in contemporary debates, with connections worth exploring in future work. ${ }^{23}$ Most prominently, Clifford's theory compares interestingly to other attempts at offering a teleological account of the social value of honesty, as in for instance Julia Annas' Aristotelian approach. ${ }^{24}$ Then too one might include Clifford's attributionism in a long history of thinking about moral responsibility, and consider

\footnotetext{
${ }^{22}$ See Dougherty, "'The 'Ethics of Belief' is Ethics (Period)" for an extensive argument that in general the ethics of belief is applied ethics rather than epistemology proper. Curiously, however, Dougherty's argument turns on the supposition that, unlike moral norms, epistemological norms are teleological (154). Clifford obviously thought otherwise.

${ }^{23}$ At his personal home page, Brian Zamulinski - uniquely among current writers - describes himself as a 'disciple of Clifford' ("Brian Zamulinski - the ethics of belief"). Yet he endorses a view rather different than that explained here.

${ }^{24}$ Annas insists that a member of the 'community formed by the honest' can 'think, act, and reason in ways that conflict with those of his own family' (Intelligent Virtue, 55).
} 
in particular Clifford's seeming agreement with Nomy Arpaly's insistence that even an 'honest mistake' can be blameworthy when it reflects a deep-seated failure to track moral truth (Unprincipled Virtue, 84).

But perhaps more salient than these philosophical themes are the implications of Clifford's rhetorical style. In a characteristic passage, prominent atheist epistemologist Simon Blackburn writes:

People sometimes say they respect the 'sincerity' of those who display passionate conviction, even when what they are convinced about is visibly false [ ... ] But surely, we ought to find passion and conviction in such a case dangerous and lamentable. [ ... ] If we sympathise with the doughty Victorian W. K. Clifford, we will see in it a sign of something worse: a dereliction of cognitive duty, or a crime against the ethics of belief, and hence, eventually, a crime against humanity.

("Religion and Respect", 181)

In the present age, rife with religious fanaticism, political tribalism and conspiratorial theorizing, Clifford's ardent call to sacrifice the temporary peace of shallow tolerance in return for an effective collective pursuit of truth is as provocative and relevant as it ever was. For Clifford, our individual veracity is ultimately what secures the survival of mankind. His work owes its durability and fame not least to the uncompromising nature of that moral vision.

\section{Acknowledgments}

We wish to thank two anonymous reviewers of the BJHP for excellent comments and suggestions.

\section{Funding}

The research was in part supported by the Danish National Research Foundation [grant number DNRF127].

\section{ORCID}

Nikolaj Nottelmann (D) http://orcid.org/0000-0002-8621-6640

Patrick Fessenbecker (D) http://orcid.org/0000-0002-4314-2872

\section{References}

Aikin, Scott F. Evidentialism and the Will to Believe. London: Bloomsbury, 2014. [Evidentialism]

Annas, Julia. Intelligent Virtue. Oxford: Oxford University Press, 2011.

Antony, Louise. "Good minus God". The Stone. New York Times, December 18, 2011. https://opinionator.blogs.nytimes.com/2011/12/18/good-minus-god/.

Arnold, Matthew. Literature and Dogma: An Essay Towards a Better Appreciation of the Bible. London: Smith, 1873. ['LaD'] 
Blackburn, Simon. "Religion and Respect". In Philosophers Without God, edited by Louise Antony, 179-193. Oxford: Oxford University Press, 2010.

Bonner, Campbell. "The Ship of the Soul on a Group of Grave-Stelae from Theranuthis". Proceedings of the American Philosophical Society 85 (1941): 84-91.

Brownstein, Michael. "Attributionism and Moral Responsibility for Implicit Bias". Review of Philosophy and Psychology 7 (2016): 765-786. [Attributionism]

Chignell, Andrew. "The Ethics of Belief". The Stanford Encyclopedia of Philosophy (Spring 2018 Edition), edited by Edward N. Zalta. https://plato.stanford.edu/archives/ spr2018/entries/ethics-belief/.

Chignell, Andrew, and Andrew Dole. "The Ethics of Religious Belief: A Recent History". In God and The Ethics of Belief, edited by Andrew Dole and Andrew Chignell, 1-27. Cambridge: Cambridge University Press, 2005.

Clifford, William Kingdon. "On Some of the Conditions of Mental Development". In Lectures and Essays, edited by Leslie Stephen and Frederick Pollock, vol. 1, 106108. London: Macmillan, 1879.

Clifford, William Kingdon. "The Ethics of Belief". In The Ethics of Belief and Other Essays, edited by Timothy J. Madigan, 70-96. New York: Prometheus Books, 1999. ['EoB']

Clifford, William Kingdon. "The Ethics of Religion". In The Ethics of Belief and Other Essays, edited by Timothy J. Madigan, 97-121. New York: Prometheus Books, 1999. ['EoR']

Clifford, William Kingdon. "Right and Wrong: The Scientific Ground of Their Distinction". In The Ethics of Belief and Other Essays, edited by Timothy J. Madigan, 28-69. New York: Prometheus Books, 1999. ['RaW']

Darwin, Charles. "The Descent of Man, and Selection in Relation to Sex", in From So Simple a Beginning: The Four Great Books of Charles Darwin, edited, with introductions by Edward O. Wilson, 765-1252. New York: Norton, 2006. [Descent of Man]

Dougherty, Trent. "The 'Ethics of Belief' is Ethics (Period)". In The Ethics of Belief, edited by Jonathan Matheson and Rico Vitz, 146-168. Oxford: Oxford University Press, 2014.

Haack, Susan. "The Ethics of Belief' Reconsidered". In The Philosophy of Roderick M. Chisholm, edited by Lewish Hahn, 129-144. Lasalle, IL: Open Court, 1997.

Harvey, Van A. "The Ethics of Belief Reconsidered". In The Ethics of Belief Debate, edited by Gerald McCarthy, 189-204. Atlanta: Scholars Press, 1986.

Hooker, Brad. "Rule Consequentialism". The Stanford Encyclopedia of Philosophy (Winter 2016 Edition), edited by Edward N. Zalta. https://plato.stanford.edu/archives/ win2016/entries/consequentialism-rule/.

Houghton, Walter. The Victorian Frame of Mind. New Haven: Yale University Press, 1957. Hume, David. A Treatise of Human Nature. 2nd ed., with text revised and variant readings by P.H. Nidditch. Oxford: Clarendon Press, 1978. [Treatise]

Hume, David. Enquiries Concerning Human Understanding and Concerning the Principles of Morals. 3rd ed., with text revised and notes by P.H. Nidditch. Oxford: Clarendon Press, 1975. [Enquiry]

James, William. The Will to Believe and Other Essays in Popular Philosophy. New York: Dover, 1956. [Will to Believe]

Kucich, John. The Power of Lies: Transgression in Victorian Fiction. Ithaca: Cornell University Press, 1993. [Power of Lies]

Levy, Neil. "The Good, The Bad, and The Blameworthy". Journal of Ethics and Social Philosophy 1 (2005): 2-16.

Madigan, Timothy J. "Introduction". In The Ethics of Belief and Other Essays, edited by Timothy J. Madigan, ix-xxii. New York: Prometheus Books, 1999. 
Madigan, Timothy J. W.K. Clifford and 'The Ethics of Belief'. Cambridge: Cambridge Scholars Publishing, 2009.

Marušić, Berislav. "The Ethics of Belief". Philosophy Compass 6 (2011): 33-43.

Mavrodes, George. "James and Clifford on 'The Will to Believe'". In The Ethics of Belief Debate, edited by Gerald McCarthy, 205-220. Atlanta: Scholars Press, 1986.

McCormick, Miriam Schleifer. Believing Against The Evidence: Agency and The Ethics of Belief. New York: Routledge, 2014. [Believing Against The Evidence]

Mill, John Stuart. On Liberty and Other Essays. New York: Oxford University Press, 2008.

Oliveira, Luis. "Clifford, William Kingdon". In The Wiley-Blackwell Companion to Philosophy of Religion. London: Wiley-Blackwell, forthcoming. https://philpapers. org/archive/OLICWK.pdf

Peels, Rik. "The Ethics of Belief and Christian Faith as Commitment to Assumptions". Religious Studies 46 (2010): 97-107.

Petrunic, Josipa. "Evolutionary Mathematics. William Kingdon Clifford's Use of Spencerian Evolutionism". In The Age of Scientific Naturalism: Tyndall and His Contemporaries, edited by Bernard Lightman and Michael S. Reidy, 89-112. London: Pickering \& Chatto, 2014.

Rescher, Nicholas. Pascal's Wager: A Study of Practical Reasoning in Philosophical Theology. South Bend, IN: University of Notre Dame Press, 1985. [Pascal's Wager]

Rowbottom, Darrell Patrick. "Kuhn Versus Popper on Criticism and Dogmatism in Science. A Resolution at the Group Level". Studies in History and Philosophy of Science Part A 42 (2011): 117-124. ['Kuhn versus Popper on Criticism and Dogmatism in Science']

Scanlon, Thomas A. What We Owe to Each Other. Cambridge, MA: Belknap, 1998.

Smith, Holly. "Culpable Ignorance". The Philosophical Review 92 (1983): 543-571.

Smith, Philip. Why Faith is a Virtue. Eugene: Cascade, 2014.

Van Inwagen, Peter. "It is Wrong Anywhere, Anywhere, for Anyone, to Believe Anything upon Insufficient Evidence". In Faith, Freedom and Rationality, edited by Jeff Jordan and Daniel Howard-Snyder, 137-154. Savage, ML: Rowman \& Littlefield, 1996.

Ward, William. "The Reasonable Basis of Certitude". In The Ethics of Belief Debate, edited by Gerald McCarthy, 171-186. Atlanta: Scholars Press, 1986.

Zamulinski, Brian. "A Re-Evaluation of Clifford and His Critics". Southern Journal of Philosophy LX (2002): 437-457.

Zamulinski, Brian. "A Defence of The Ethics of Belief". Philo 7 (2004): 79-96.

Zamulinski, Brian. "Christianity and the Ethics of Belief". Religious Studies 44 (2008): 333346.

Zamulinski, Brian. "The Cliffordian Virtue". European Journal for Philosophy of Religion 5, no. 3 (2013): 159-176

Zamulinski, Brian. "Brian Zamulinski - The Ethics of Belief". Personal homepage. Stable url: http://zamulinski.com/the_ethics_of_belief. Retrieved 22 December 2018. 